\title{
Coordinated Release of ATP and ACh from Cholinergic Synaptosomes and Its Inhibition by Calmodulin Antagonists
}

\author{
Erik Schweitzer \\ Department of Anatomy, University of Wisconsin, Madison, Wisconsin 53706
}

\begin{abstract}
Isolated cholinergic synaptosomes from elasmobranch electric organ release both ACh and ATP when depolarized in the presence of calcium. The conditions that trigger ATP release are the same as those known to stimulate neurosecretion. The ratio of ACh to ATP released is the same as that found in purified elasmobranch synaptic vesicles. Both ACh and ATP release are inhibited either by the removal of extracellular calcium or the addition of the "calmodulin antagonist" trifluoperazine (TFP). Taken together, these data suggest that both ACh and ATP are released by exocytosis from synaptic vesicles within nerve terminals.

A number of drugs, collectively known as calmodulin antagonists, were examined for their effect on neurosecretion. TFP completely inhibited secretion in a rapid and reversible manner. Other related drugs had similar effects, though with relative efficacies different from those reported for inhibiting calmodulin. It therefore seems likely that a calmodulin-like component of the nerve terminal, distinct from calmodulin itself, is essential for the process of neurosecretion.
\end{abstract}

The mode of release of $\mathrm{ACh}$ from nerve terminals remains a matter of some controversy. There is a large body of evidence, both electrophysiological and morphological, that supports the vesicle hypothesis of transmitter release, namely, that $\mathrm{ACh}$ is stored in synaptic vesicles and is released from the presynaptic terminal when these vesicles fuse with the plasma membrane. However, biochemical experiments designed to test the vesicle hypothesis have yielded conflicting results. The preparation of choice for such experiments has been the electric organ of the marine ray, which has a dense, purely cholinergic innervation. While the purification of synaptic vesicles from electric organ demonstrated that they contain high concentrations of ACh (Whittaker et al., 1972; Wagner et al., 1978), the direct release of this vesicular $\mathrm{ACh}$ has been difficult to observe. In fact, Israel and colleagues carried out a series of experiments demonstrating that, under certain conditions, $\Lambda \mathrm{Ch}$ can be released directly from cytoplasmic pools (Israel et al., 1981) and that ACh release can be observed from proteoliposomes reconstituted from synaptosomal membranes (Israel et al., 1984). These results have led

Received Nov. 17, 1986; revised Jan. 26, 1987; accepted Mar. 10, 1987.

I thank Reg Kelly, in whose laboratory this work was carried out, for support and encouragement, as well as many useful discussions, and Hsiao-Ping Moore for her help with the calcium-flux experiments. I also thank Leslie Spector and Sue Leonard for their expert help and patience in preparing the manuscript. This work was supported by a postdoctoral fellowship from the Muscular Dystrophy Association.

Correspondence should be addressed to Erik Schweitzer, Department of Anatomy, University of Wisconsin-Madison, 1300 University Avenue, Madison, WI 53706.

Copyright @ 1987 Society for Neuroscience $0270-6474 / 87 / 092948-09 \$ 02.00 / 0$ to a model that neurosecretion of ACh occurs through a channel in the plasma membrane rather than by vesicle fusion (Israel et al., 1984).

Since cholinergic vesicles contain ATP as well as ACh (Wagner et al., 1978), the vesicle hypothesis leads to the testable prediction that both these compounds should be released together from cholinergic nerve terminals. In fact, Silinsky (1975) has reported that ATP and ADP can be recovered from stimulated neuromuscular preparations. Such release has also been observed from stimulated electric organ (Israel and Meunier, 1978) and electric organ synaptosomes (Morel and Meunier, 1981); a large part of the release from the intact organ is postsynaptic in origin, and it is not clear whether the stoichiometry of the presynaptic release is consistent with the vesicle hypothesis. In view of these results, it seemed desirable to examine a preparation of cholinergic nerve terminals in the absence of postsynaptic cells, such as is provided by synaptosomes from electric organ (Morel et al., 1977). The results presented here demonstrate that ATP is released along with ACh under conditions that would be expected for transmitter release and that the relative amounts of ACh and ATP are the same as have been found in purified synaptic vesicles from the same source. These results therefore strongly support the vesicle model of ACh release.

In addition, the finding that ATP release parallels transmitter release permitted the use of ATP as a convenient marker to study the properties of neurosecretion from isolated nerve terminals. In particular, the involvement of calmodulin-like components was explored. Since transmitter release is triggered by changes in intracellular $\mathrm{Ca}^{2+}$ in the range of $10^{-7}$ to $10^{-6} \mathrm{M}$, it seems certain that cellular components with high-affinity binding sites for $\mathrm{Ca}^{2+}$ must be involved. Calmodulin is one such molecule that has been shown to modulate a wide variety of cellular responses, including phosphodiesterase activity (Levin and Weiss, 1976), contractile processes (Yagi et al., 1978), and ion channels (Wada et al., 1983). Calmodulin may be involved in cellular secretion as well, as demonstrated by the observation that anti-calmodulin antibodies can block the degranulation reaction of sea urchin eggs (Steinhardt and Alderton, 1982) and release of catecholamines from adrenal chromaffin cells (Kenigsberg and Trifaro, 1985). A group of phenothiazine drugs interact at high affinity with calmodulin and block its effects (Levin and Weiss, 1976); these compounds have come to be known as calmodulin antagonists and have been used to provide evidence for the involvement of calmodulin in cellular processes, including secretion (Douglas and Nemeth, 1982; Knight and Baker, 1982). However, it is now clear that calmodulin is just one of a family of proteins that bind to phenothiazines in a Ca-dependent manner (Moore and Dedman, 1982). The relative affinities 
of these proteins for various phenothiazines may differ from that seen with calmodulin; such is the case with synexin, a calcium-binding protein that causes Ca-dependent aggregation of chromaffin granules (Creutz et al., 1978). The possible involvement of calmodulin and calmodulin-like proteins in neural cell secretion has been difficult to evaluate directly because of postsynaptic effects of calmodulin antagonists (Cheng et al., 1981). However, DeLorenzo (1982) has suggested a number of possible sites for such an involvement, including protein phosphorylation and vesicle-membrane interactions, and has presented evidence that calmodulin inhibitors decrease $\mathrm{ACh}$ and catecholamine release from brain synaptosomes.

The results presented here indicate that trifluoperazine (TFP) completely blocks the release of both ACh and ATP in a rapid and reversible manner. In addition, release is blocked by a variety of "calmodulin antagonists," including the structurally dissimilar drugs W-5 and W-7. Surprisingly, the relative cffectiveness of these drugs in blocking ATP release does not match that seen with calmodulin, suggesting that a related $\mathrm{Ca}$-sensitive protein, rather than calmodulin itself, is involved.

\section{Materials and Methods}

Solutions. Isotonic elasmobranch saline $[\mathrm{Na}(+\mathrm{Ca})]$ contained the following: $280 \mathrm{~mm} \mathrm{NaCl}, 3.0 \mathrm{~mm} \mathrm{KCl}, 1.8 \mathrm{~mm} \mathrm{MgCl}, 3.4 \mathrm{~mm} \mathrm{CaCl}, 300$ $\mathrm{mm}$ urea, $100 \mathrm{~mm}$ sucrose, $5.5 \mathrm{~mm}$ glucose, and $40 \mathrm{~mm}$ HEPES, $\mathrm{pH}$ 7.4. Calcium-free saline $[\mathrm{Na}(\mathrm{OCa})]$ was the same except for the omission of $\mathrm{CaCl}_{2}$. Depolarizing solutions $[\mathrm{K}(+\mathrm{Ca})$ and $\mathrm{K}(0 \mathrm{Ca})]$ were similar to the $\mathrm{Na}$ solutions but with $\mathrm{K}$ substituted on a molar basis for Na. EGTA, when used, was added as Mg-EGTA, pII 7.4, to avoid any pII changes resulting from the chelation of $\mathrm{Ca}^{2+}$. All solutions used for storing and manipulating purified synaptosomes also contained 1\% BSA (recrystallized and lyophilized; Sigma).

Initially, all fish were perfused with an isotonic salt solution containing $10 \mathrm{~mm}$ EGTA and $20 \mathrm{~mm} \mathrm{NaNO}$. However, identical results were obtained from nonperfused fish, and this practice was discontinued for later experiments.

TFP was made up as a stock solution of $1 \mathrm{~mm}$ in DMSO and stored at $-20^{\circ} \mathrm{C}$ in the dark. For use, this stock solution was diluted directly into buffer solutions. The calmodulin antagonists W-5 and W-7 were obtained from Rikaken Company Limited, Japan.

Synaptosomes. Most experiments were carried out with synaptosomes made from the electric organ of the marine ray, Ommata discopyge. For some cxperiments, synaptosomes from Torpedo californica wcrc used instead. Similar results were obtained with both preparations; however, compared with Ommata, Torpedo synaptosomes exhibited a higher basal rate of leakage of ACh, but not of ATP.

Synaptosomes were prepared by a modification of the method of Miljanich et al. (1982) as follows. Electric organs were excised from anesthetized ( $0.25 \mathrm{gm}$ Tricaine/liter seawater) fish, and the organs were immediately immersed in an equal amount (wt/vol) of $\mathrm{Na}(\mathrm{OCa})$ buffer containing $1 \mathrm{mM}$ EGTA. The tissue was homogenized in a Waring blender with $4 \times 15 \mathrm{sec}$ bursts, interspersed with immersion in an ice bath to prevent warming. Pieces of connective tissue were removed by filtration through a coarse $(40 \mathrm{mesh})$ stainless steel filter, and the resulting homogenate was centrifuged at $30,000 \times g$ for $15 \mathrm{~min}$ at $4^{\circ} \mathrm{C}$. The pellet was resuspended in $\mathrm{Na}(0 \mathrm{Ca})$ buffer without added EGTA and dispersed with a loose-fitting glass-Teflon homogenizer. After recentrifugation at $30,000 \times g$ for $15 \mathrm{~min}$, the pellet was again resuspended in $\mathrm{Na}(0 \mathrm{Ca})$, dispersed, and layered on top of a continuous linear $5-15 \%$ Ficoll gradient in $\mathrm{Na}(\mathrm{OCa})$ buffer. This density gradient was spun at $80,000 \times g$ for $60 \mathrm{~min}(25,000 \mathrm{rpm}$ in an $\mathrm{SW} 27$ rotor $)$, and the band containing synaptosomes (refractive index $=1.353$ ) was removed. The synaptosomes were diluted 4-fold with $\mathrm{Na}(0 \mathrm{Ca})$ buffer and pelleted at $30,000 \times g$ for $15 \mathrm{~min}$. They were then resuspended in a small volume of $\mathrm{Na}(0 \mathrm{Ca})$ buffer containing $1 \% \mathrm{BSA}$ (crystallized and lyophilized; Sigma) and stored at $0^{\circ} \mathrm{C}$. Under these conditions, the synaptosomes were stable for several days. Omission of BSA significantly reduced the long-term stability of the synaptosomes.

Protein was determined by the method of Bradford (1976) on parallel aliquots suspended without BSA.
ATP assays. ATP was monitored with the firefly luciferin-luciferase system (Karl and Holm-Hansen, 1976). Firefly extracts (Sigma) were reconstituted in $\mathrm{H}_{2} \mathrm{O}$ and passed over a Sephadex $\mathrm{G}-25$ column to remove arsenate and other small molecules that proved deleterious to the stability of synaptosomes. This cleaned extract was separated into aliquots, lyophilized, and stored at $-20^{\circ} \mathrm{C}$ until use. At that time, the aliquots were reconstituted in $1 \% \mathrm{BSA}$ in $\mathrm{Na}(0 \mathrm{Ca})$ buffer, and $1 \mathrm{mg} / \mathrm{ml}$ synthetic luciferin (Sigma) was added.

For measuring ATP release from synaptosomes, $50 \mu \mathrm{l}$ of luciferinluciferase (L-L) mixture was added to $450 \mu \mathrm{l}$ saline, usually $1 \%$ BSA in $\mathrm{Na}(\mathrm{Ca})$. An aliquot of the synaptosomal suspension was then added, and the test tube was placed in an LKB luminometer to monitor light output. The baseline usually stabilized within several seconds to a low level of luminescence. Synaptosomes were then stimulated by the addition, through a light-tight septum, of an equal volume $(500 \mu \mathrm{l})$ of depolarizing $[\mathrm{K}(+\mathrm{Ca})]$ medium containing $50 \mu \mathrm{l}$ of the $\mathrm{L}-\mathrm{L}$ mix. Responses were quantitated by subsequent addition of ATP standards. Any effects of synaptosomal AT Pases were thus compensated for by the routine addition of these standards to the assay mixture containing the synaptosomes. Measuring either the peak height or peak area of the light output gave equivalent results; peak heights were generally used for convenience. The response of the assay to standard amounts of ATP was linear over the range used for these measurements.

Total synaptosomal ATP was measured by heating synaptosomes to $95^{\circ} \mathrm{C}$ in $\mathrm{H}_{2} \mathrm{O}$ for $2 \mathrm{~min}$ to release all ATP. This extract was then assayed for ATP as above.

$A C h$ assay. ACh was assayed with a modification of the luminometric assay described by Israel and Lesbats (1981). The most noteworthy difference was that the incubation was carried out at $\mathrm{pH} 7.4$ rather than 8.6. Stock solutions of $200 \mathrm{U} / \mathrm{ml}$ ACh-esterase (from electric eel; Sigma), $500 \mathrm{U} / \mathrm{ml}$ choline oxidase (from Alcaligenes species; Sigma), $1 \mathrm{mg} / \mathrm{ml}$ HRP (Sigma), and $10 \mathrm{~mm}$ luminol (5-amino-2,3-dihydro-1,4-phthalazinedione; Sigma) were made up in $\mathrm{Na}(\mathrm{OCa})$ buffer; the choline oxidase and luminol were allowed to incubate overnight at $4^{\circ} \mathrm{C}$ before use and were never frozen. ACh release was measured by adding approximately $100 \mu \mathrm{g}$ synaptosomes to $500 \mu \mathrm{l} \mathrm{Na}$ (+Ca) buffer, $\mathrm{pH} 7.4$, containing $1 \%$ $\mathrm{BSA}$, and the following final concentrations of reagents: $1 \mathrm{U} / \mathrm{ml} \mathrm{ACh-}$ esterase, $20 \mathrm{U} / \mathrm{ml}$ choline oxidase, $5 \mu \mathrm{g} / \mathrm{ml}$ peroxidase, and $50 \mu \mathrm{M}$ luminol. This mixture was then placed in an LKB luminometer, and the synaptosomes were stimulated by the addition of $500 \mu \mathrm{l}$ of a $\mathrm{K}(+\mathrm{Ca})$ solution containing the same amounts of BSA and all the assay reagents. Responses were quantitated by measuring the light output integrated over $150 \mathrm{sec}$ after stimulation. The assay was calibrated by adding $\mathrm{ACh}$ standards directly to the incubation suspensions following stimulation. Responses in both the ACh and ATP assays were linear with respect to the amount of synaptosomes added.

Calcium fluxes. Calcium influx into synaptosomes was measured by incubating synaptosomes in $\mathrm{Na}(+\mathrm{Ca})$ buffer containing $1 \% \mathrm{BSA}$ at room temperature. Aliquots of this suspension were added to the appropriate incubation solutions containing ${ }^{45} \mathrm{Ca}$ (Amersham), at a final specific activity of about $5 \mathrm{Ci} / \mathrm{mol}$. After incubation for the specified time, the synaptosomes were separated from the bathing medium by rapid filtration using $0.2 \mu \mathrm{m}$ Millipore filters in a Millipore manifold. The filters were washed twice with $\mathrm{Na}(+\mathrm{Ca})$ and then removed and counted in a scintillation counter. Filter blanks were performed in parallel by filtering incubation solutions without membranes, and these values were subtracted from the experimental points.

\section{Results}

The first goal of the experiments presented here was to establish whether ATP is released from cholinergic nerve terminals along with ACh during neurosecretion. This is important both experimentally and conceptually. The use of ATP as a marker for neurosecretion offers substantial experimental advantages over measurements of $\mathrm{ACh}$ in that it can be monitored in real time with high sensitivity and with minimal perturbations from physiological conditions. In contrast, sensitive biochemical measurements of ACh release are difficult to perform with high time resolution. The luminometric assay of Israel and Lesbats (1981) was used by these workers at $\mathrm{pH} 8.6$; the sensitivity of the assay is several orders of magnitude less sensitive at $\mathrm{pH} 7.4$. Since significant differences were observed for some properties (par- 
ticularly the calcium sensitivity) of transmitter release between pH 7.4 and 8.6 (data not shown), it seemed desirable to carry out further studies under conditions as close to physiological as possible. In addition to this technical problem of assaying $\mathrm{ACh}$, there is the additional complication of the possible contribution of nonquantal secretion, which has been shown to occur from resting cholinergic synapses (Katz and Miledi, 1977). Conceptually, it was important to determine whether ATP is released as part of the neurosecretory process, since this prediction of the vesicle hypothesis has not been convincingly demonstrated in cholinergic systems. The first series of experiments described here therefore define the conditions under which cholinergic nerve terminals release ATP.

When electric organ synaptosomes were placed in an isotonic, nondepolarizing medium in the presence of $\mathrm{L}-\mathrm{L}$, they remained stable for long periods of time and released very little ATP into the medium. Figure $1 a$ shows that the addition of $\mathrm{Na}$-containing medium also containing L-L (so that the final concentration of these reagents was unchanged) did not cause any additional ATP release. In contrast, depolarizing the synaptosomes by the addition of a K-containing solution resulted in a burst of ATP release (Fig. $1 b$ ). This release was rapid, peaking within the resolution of the assay $(1-2 \mathrm{sec})$ and appeared to be completed in less than $10 \mathrm{sec}$. The release is therefore phasic, even in the presence of continued depolarization. In addition, this ATP release required extracellular $\mathrm{Ca}^{2+}$, since there was no release when synaptosomes were depolarized in the absence of $\mathrm{Ca}^{2+}(1$ mM EGTA; Fig. 1c), even though the sensitivity of the ATP assay, under these conditions with $1.8 \mathrm{mM} \mathrm{MgCl}_{2}$, is increased. (Note the difference in the signal produced by the ATP standard in Fig. 1, $a$ and c.) The addition of standard amounts of ATP directly to the incubation mixture permitted the calculation of the amount of ATP released while compensating for any variations due to changes in assay sensitivity of endogenous ATPase activity. The amount of ATP released by optimal stimulation, as shown here, consistently represented approximately $5 \%$ of the total synaptosomal ATP. Control experiments demonstrated that prolonged incubation (up to $2 \mathrm{hr}$ ) of synaptosomes in $\mathrm{K}(+\mathrm{Ca})$ medium did not cause significant release of the cytoplasmic enzyme, choline acetyltransferase (data not shown). The ATP release shown in Figure 1 is therefore not the result of gross disruption of the nerve terminals with resulting leakage of cytoplasmic contents.

It is important for the interpretation of these results to establish that the ATP release observed with $\mathrm{K}$ stimulation comes from nerve terminals and not from contaminating structures present in the synaptosomal preparation. The most likely candidates for such an artifact are mitochondria, since they could contain and potentially release substantial amounts of ATP. Although electric organ synaptosomal preparations, unlike brain synaptosomes, contain very few free mitochondria or postsynaptic membranes (Morel et al., 1977), release experiments similar to those presented in Figure 1 were carried out in the presence of mitochondrial poisons. Preincubation of synaptosomes with $100 \mu \mathrm{M}$ atractyloside, which prevents ATP transport across mitochondrial membrancs (Bruni and Azzonc, 1964), had no effect on the K-stimulated ATP release (Table 1). Moreover, the addition of the mitochondrial uncoupler FCCP $(20 \mu \mathrm{M})$ had no immediate effect on ATP release. FCCP did cause a delayed, slow release of ATP; this could either be an indirect effect of increased cytoplasmic $\mathrm{Ca}^{2+}$ as a consequence of uncoupling mitochondria within nerve terminals, or a direct depolarizing effect

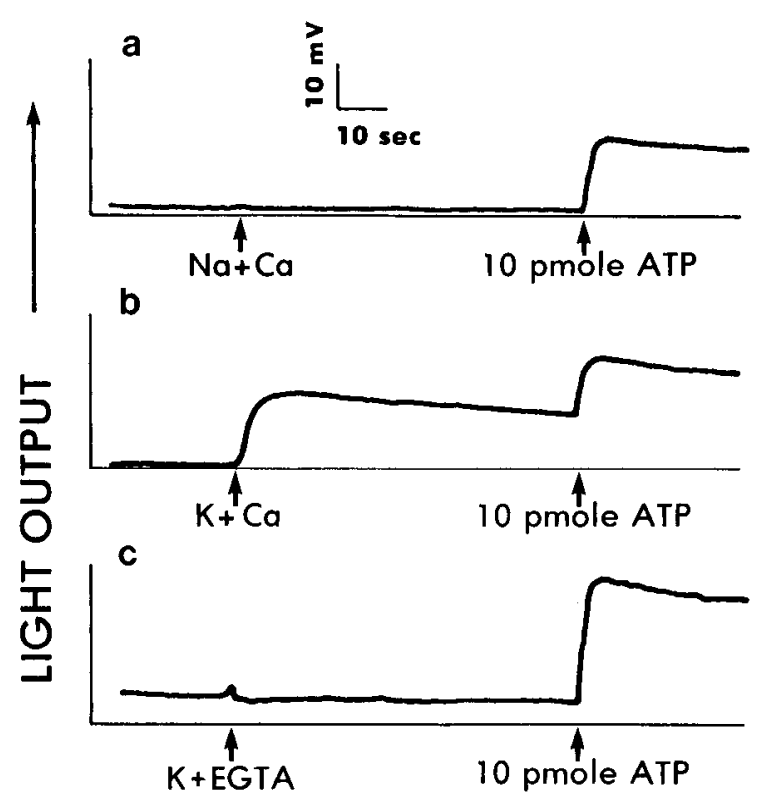

Figure 1. ATP release from electric organ synaptosomes. Ommata synaptosomes $(0.8 \mu \mathrm{g}$ protein) were added to $0.5 \mathrm{ml}$ assay medium containing luciferin-luciferase as described in Materials and Methods and placed in a luminometer. ATP release was quantitated by monitoring light output. At the first arrow, $0.5 \mathrm{ml}$ of various media was added into the suspension through a lighttight septum using a syringe and needle. This addition both altered the bathing medium (without altering the concentration of luciferin-luciferase) and mixed the samples. At the second arrow, a standard amount of ATP was added in $10 \mu \mathrm{l}$ using a Hamilton syringe. This signal was used to calculate the amount of ATP release from the synaptosomes. In $a, 0.5 \mathrm{ml}$ of $\mathrm{Na}+\mathrm{Ca}$ medium was added, resulting in no change in the bathing medium. In $b, \mathbf{K}$ was substituted for $\mathrm{Na}$, resulting in a final $[\mathrm{K}]=140 \mathrm{mM}$. In $c$, synaptosomes were suspended in the same $\mathrm{Na}$ buffer described above except for the omission of $\mathrm{Ca}$; the stimulation solution contained $140 \mathrm{~mm} \mathrm{KCl}$, no added $\mathrm{Ca}$, and $1 \mathrm{~mm} \mathrm{Mg-EGTA}$, resulting in a free [Ca] of less than 10 nм. Control experiments demonstrated the preincubation of synaptosomes in the absence of $\mathrm{Ca}$ did not, by itself, alter the subsequent ability of those synaptosomes to release ATP, providing free $\mathrm{Ca}$ was present during depolarization (see Fig. 3).

on the plasma membrane due to the imperfect selectivity of FCCP as a cation carrier. These experiments appear to rule out mitochondria as the source of ATP release. The possibility that ATP is released from postsynaptic contaminants of the preparation as a secondary effect of presynaptic $\mathrm{ACh}$ release was eliminated by the observation that cholinergic agonists did not stimulate ATP release (Table 1), as had been reported to occur from the postsynaptic cells in preparations of intact, perfused electric organ preparations (Israel and Meunier, 1978).

It is also necessary to ask whether the ATP release is a reflection of neurosecretion or some separate process carried out by the nerve terminals. If this release results from the $\mathrm{Ca}$-dependent fusion of synaptic vesicles with the plasma membrane, there are several predictions that one can make. The release should be graded with increasing depolarization, it should be modulated by the concentration of $\mathrm{Ca}$ in the bathing medium, and it should be accompanicd by the rclcasc of other vesicle contents, such as ACh. As a corollary to this last point, treatments that modify ATP release should also alter the release of ACh.

The effects of graded depolarization on ATP release are shown in Figure 2. The amount of $\mathrm{K}$ in the stimulating solution was adjusted to produce final concentrations of 3.0-200 mM. Under 


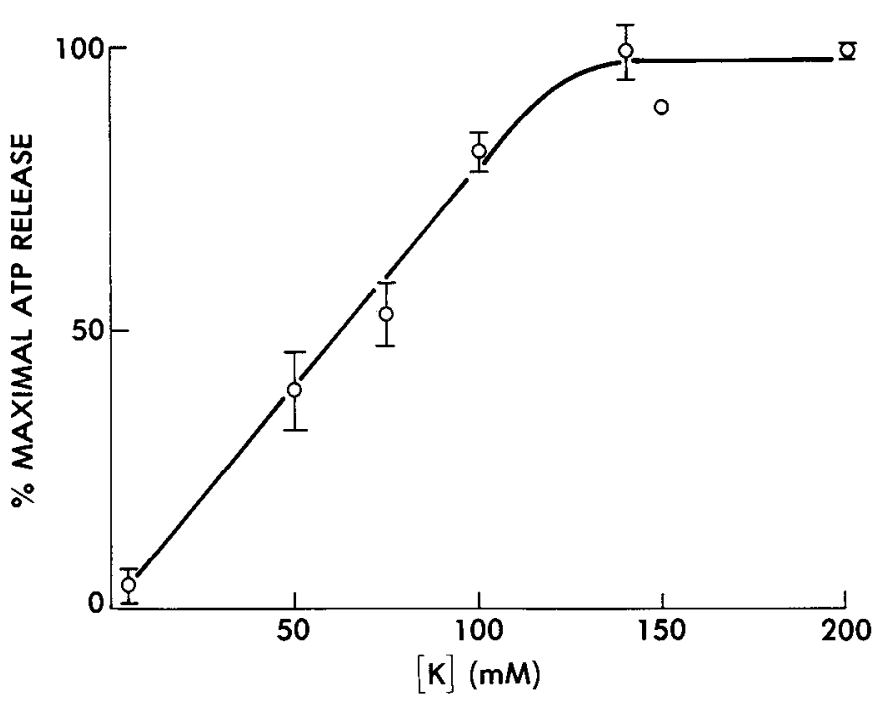

Figure 2. ATP release as a function of $\mathrm{K}$ concentration. Synaptosomes were added to $150 \mu \mathrm{l}$ of $\mathrm{Na}^{+} \mathrm{Ca}$ solution plus $\mathrm{L}-\mathrm{L}$ and placed in a luminometer to establish a baseline of luminescence. The stimulating solution was then added to the suspension: This solution was identical to the initial bathing medium except for the substitution of from 0 to $267 \mathrm{mM} \mathrm{KCl}$ for $\mathrm{NaCl}$, resulting in final $\mathrm{KCl}$ concentrations of 3-200 mM. Data shown are average of 2 different preparations of synaptosomes assayed on separate days. Error bars indicate SD (150 mM point is a single determination).

these conditions, ATP release increased continuously up to 140 mM K. Further increases above this level produced no change in the amounts of ATP released. Although varying the $\mathrm{K}$ concentration altered the magnitude of ATP release, it had no detectable effect on the rapidity of the release. A similar relationship has been reported between $\mathrm{ACh}$ release and depolarization in Torpedo synaptosomes (Meunier, 1984). In view of this result, all other experiments reported here were carried out using a final concentration of $143 \mathrm{~mm} \mathrm{~K}$ for depolarization, so that any variations in $\mathrm{K}$ concentration should have no effect on the amount of ATP released.

Figure 3 illustrates the quantitative dependence of ATP release on external $\mathrm{Ca}$ concentration. As indicated by the experiment shown in Figure 1, depolarization in the absence of $\mathrm{Ca}$ caused no release of ATP. The amount of ATP released increased as the $\mathrm{Ca}$ concentration was raised and was maximal at the physiological level of $3.4 \mathrm{~mm}$. In the experiment shown, the relationship between ATP release and external Ca does not indicate cooperativity (Hill coefficient $=1.2$ ). Previous reports of this relationship in a variety of other systems have given values from 1 (Llinás et al., 1982) to 4 (Dodge and Rahamimoff, 1967). Since both the plateau level and the precise slope of the release

\section{Table 1. Pharmacology of ATP release}

\begin{tabular}{lcl} 
Treatment & $\begin{array}{l}\text { Resting release } \\
\text { (nmol ATP/mg } \\
\text { protein) }\end{array}$ & $\begin{array}{l}\text { Depolarization- } \\
\text { stimulated } \\
\text { release }(\mathrm{nmol} \\
\text { ATP/mg } \\
\text { protein) }\end{array}$ \\
\hline Control & $0 \pm 0.02$ & $2.35 \pm 0.13$ \\
$1 \mathrm{mM}$ carbachol & $0.034 \pm 0.026$ & $2.51 \pm 0.11$ \\
$100 \mu \mathrm{M}$ atractyloside & $-0.005 \pm 0.015$ & $2.84 \pm 0.32$ \\
$20 \mu \mathrm{M}$ TFP & $0.020 \pm 0.01$ & $0.40 \pm 0.12$ \\
\hline
\end{tabular}

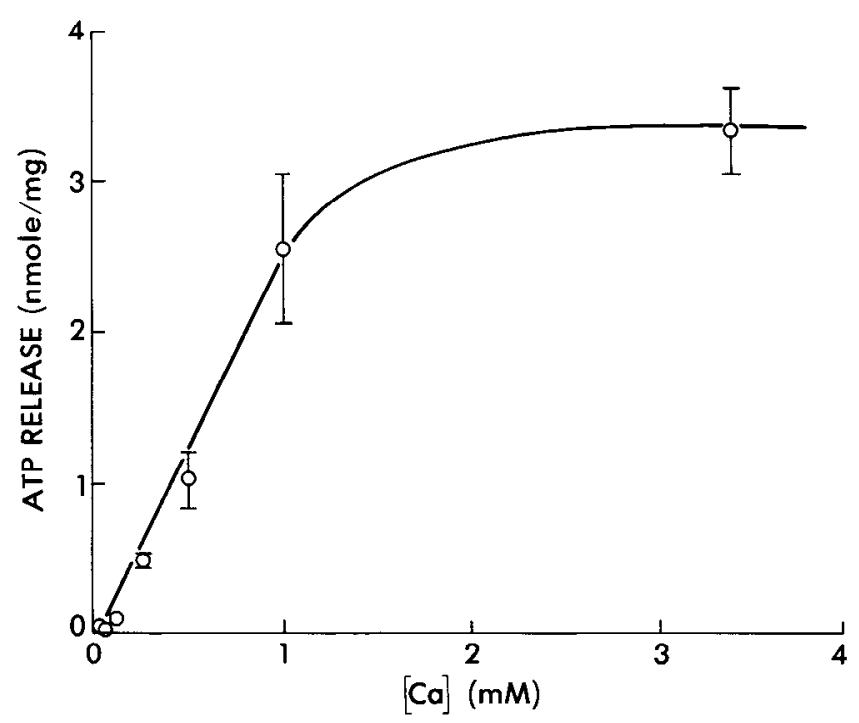

Figure 3. ATP release as a function of calcium concentration. Synaptosomes were suspended in $0.5 \mathrm{ml} \mathrm{Na}(0 \mathrm{Ca})$ buffer containing $\mathrm{L}-\mathrm{L}$, and stimulated with $0.5 \mathrm{ml}$ of $\mathrm{K}$ buffer containing varying amounts of $\mathrm{CaCl}_{2}$. The final concentration of calcium ranged from $10 \mu \mathrm{M}$ to 3.4 mM. ATP responses were quantitated by adding standards directly to the assay solutions as shown in Figure 1; this was necessary because the sensitivity of the luciferase assay decreases with $[\mathrm{Ca}]>0.25 \mathrm{~mm}$. Solid curve was drawn by eye.

curve varied somewhat from one synaptosomal preparation to another, it seems likely that these differences reflect varying extents of $\mathrm{Ca}$ loading of the nerve terminals. The range of plateau levels for ATP was estimated to be from 2.5 to $4 \mathrm{~mm}$ in different preparations.

In order to determine whether ATP is released from the nerve terminals in parallel with $\mathrm{ACh}, \mathrm{ACh}$ release was monitored with a variation of the luminometric assay developed by Israel and Lesbats (1981). Such parallel measurements permitted a direct comparison of the amounts of ATP and ACh released by various conditions. As shown in Figure 4, ACh is released by the same conditions shown to trigger the release of ATP. Depolarization in the presence of Ca causes a release of both ATP and ACh, while neither compound is released by the addition of nondepolarizing medium or by depolarizing medium plus EGTA. The molar ratio of ACh to ATP released is $2.3 \pm 0.3$ ( 3 separate preparations), a ratio similar to the 2.8 reported for purified cholinergic vesicles by Wagner et al. (1978). The stoichiometry observed for this release supports the conclusion that the release is occurring by exocytosis of synaptic vesicle contents.

In further investigations of the correlation between ACh and ATP release, it became apparent that calmodulin antagonists had a dramatic effect on the secretion of both compounds. As shown in Figure 4, the addition of $20 \mu \mathrm{M}$ TFP before stimulation completely blocked the release of both ATP and ACh. In view of the findings noted above on the parallel behavior of $\mathrm{ACh}$ and A'P secretion, it seemed desirable to use ATP release as a marker for studying the effects of calmodulin antagonists on exocytotic transmittcr relcasc more fully.

At high concentrations, calmodulin antagonists can have nonspecific effects on membranes. It was therefore important to demonstrate that TFP was effective at the low concentrations known to inhibit calmodulin. The dose-response curve for the effect of TFP on ATP release is shown in Figure 5. Half-maximal inhibition of ATP release was obtained at about $4 \mu \mathrm{M}$ TFP, and 


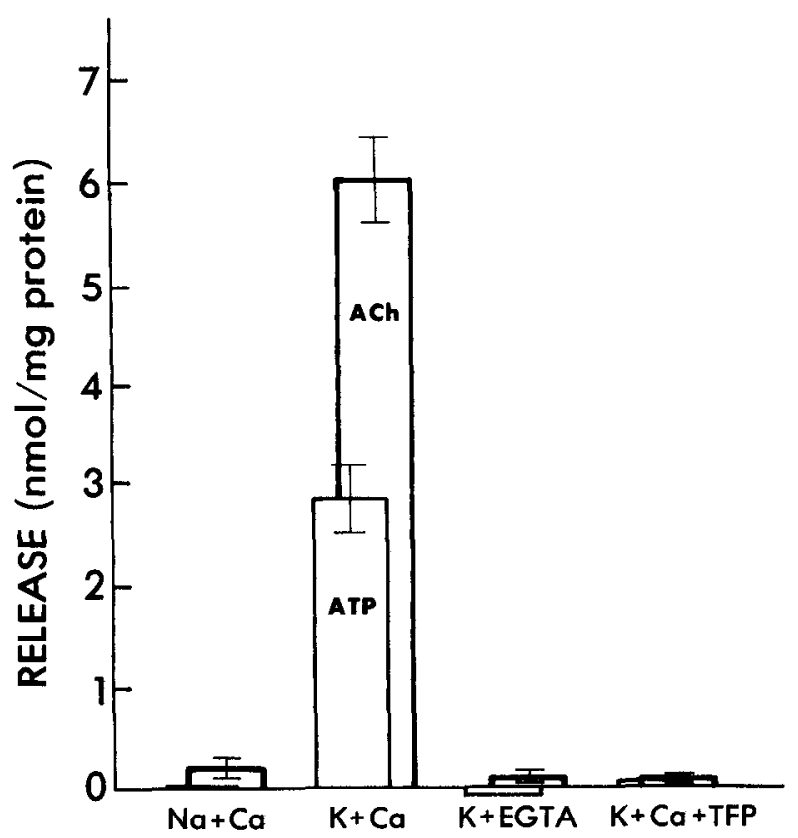

Figure 4. Comparison of ATP and ACh released from synaptosomes. Suspensions of synaptosomes were assayed for release of ACh and ATP as described in Materials and Methods. For ACh determinations, $60 \mu \mathrm{g}$ synaptosomes were used for each determination, while for ATP, $6 \mu \mathrm{g}$ synaptosomes were used. In this experiment, the ACh/ATP ratio was 2.1. Error bars indicate the range of duplicate determinations.

$20 \mu \mathrm{M}$ TFP was sufficient to block release completely. Incubation of synaptosomes with TFP for times $>30 \mathrm{sec}$ did not alter this dose-response relationship.

The records shown in Figure 6 illustrate an cxpcriment in which TFP was added a short time before stimulation of the synaptosomes and demonstrate 2 significant properties of the effect of TFP on ATP release. First, the effect was rapid, occurring within $60 \mathrm{sec}$ after adding the drug. This is consistent with the lipophilic nature of TFP and the lack of any large diffusion barriers in the suspension of synaptosomes, as are present in intact tissues. Second, TFP, by itself, did nol cause the release of significant amounts of ATP. Therefore, it is not possible to account for the subsequent decrease in depolarization-stimulated ATP release by a decrease in the releasable pool. This suggests that the ATP is retained within the terminal but that the release process itself is blocked.

This conclusion is confirmed by the observation that the inhibition caused by TFP is rapidly reversible, as shown in Figure 7. In this experiment, synaptosomes were preincubated in a small volume with $20 \mu \mathrm{M}$ TFP and then diluted 100 -fold for various times prior to depolarization. The amount of ATP released by these synaptosomes returned to $88 \%$ of control levels within $30 \mathrm{sec}$ after the dilution. This result clearly demonstrates that the inhibition caused by TFP is not due to degradation of ATP or to a permanent disruption of membranes and supports the hypothesis that it acts by reversible binding to a specific target site within the nerve terminal.

Since calmodulin antagonists inhibit $\mathrm{Ca}$ channels in some systems, it was important to determine whether TFP acts on electric organ synaptosomes by blocking $\mathrm{Ca}$ influx. Synaptosomes were therefore incubated under the same conditions used to stimulate ATP and $\mathrm{ACh}$ release but with ${ }^{45} \mathrm{Ca}$ present in the bath. Synaptosomes incubated in nondepolarizing medium took

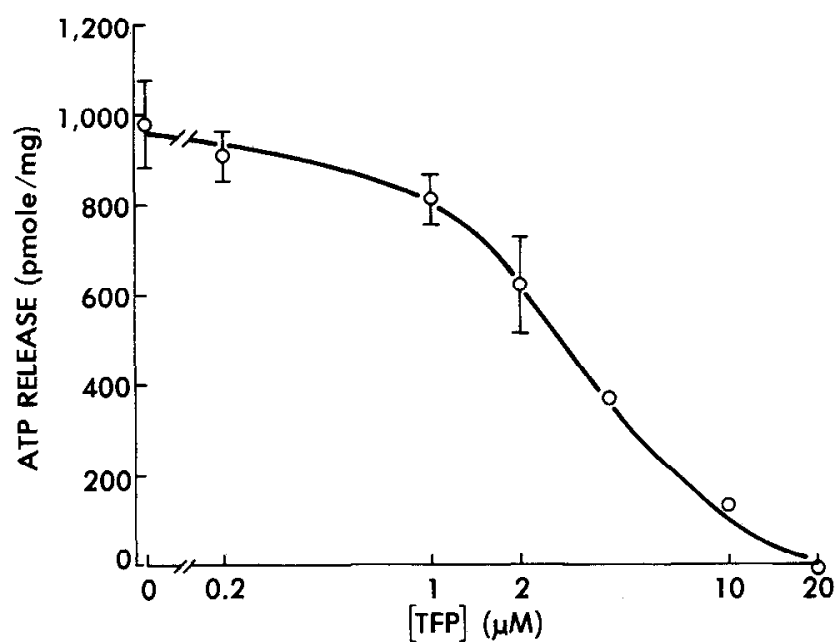

Figure 5. Concentration dependence of TFP-induced inhibition of ATP release. Synaptosomes were preincubated for $5 \mathrm{~min}$ in $\mathrm{Na}(+\mathrm{Ca})$ buffer containing $\mathrm{L}-\mathrm{L}$ and varying amounts of TFP from 0 to $20 \mu \mathrm{M}$ (diluted from a $1 \mathrm{mM}$ stock in DMSO). Suspensions were then placed in the luminometer and stimulated with a $\mathrm{K}(+\mathrm{Ca})$ solution also containing L-L and TFP. Neither TFP nor DMSO by themselves had any effect on the luciferase assay; DMSO itself did not inhibit release of ATP from synaptosomes.

up very little $\mathrm{Ca}$ (Fig. 8), consistent with the lack of transmitter release under these conditions. In contrast, depolarizing the synaptosomes with $\mathrm{K}$ resulted in a large increase in the rate of $\mathrm{Ca}$ influx. The rate of this (unidirectional) flux in the presence of continued depolarization is constant for more than a minute. The addition of $20 \mu \mathrm{M} \mathrm{TFP}$, an amount sufficient to completely inhibit transmitter release, did not block $\mathrm{Ca}$ influx, suggesting that TFP is not acting at the level of the $\mathrm{Ca}$ channel but at a subsequent step in the secretory process.

To get additional information about the site of action of TFP, I examined the effects of a variety of compounds known to interact with calmodulin. These included promethazine, another phenothiazine with close structural similarities to TFP, as well as the structurally dissimilar calmodulin antagonists $\mathrm{W}-5$ and W-7. All these compounds inhibit calcium-calmodulin activation of phosphodiesterase, though at widely different concentrations. Promethazine, for example, is more than an order of magnitude less effective than TFP in inhibiting calmodulin activation of phosphodiesterase (Levin and Weiss, 1976). When these drugs are incubated with synaptosomes, they are all effective in blocking ATP release and differ only in the concentrations required for this inhibition (Fig. 9). The concentrations required for half-maximal inhibition of depolarization-stimulated ATP release $\left(\mathrm{IC}_{50}\right)$ are 5.6 and $25 \mu \mathrm{M}$ for TFP and promethazine, and 18 and $41 \mu \mathrm{M}$ for W-7 and W-5, respectively. Thus, although each of these "calmodulin antagonists" was effective at inhibiting secretion, the relative efficacies they exhibited differed from those reported for calmodulin itself.

\section{Discussion}

The experiments described here are based on an in vitro system for measuring the release of both ACh and ATP from purified nerve terminals, in the absence of any postsynaptic elements. The properties of this release strongly suggest that it is the result of the normal process of neurotransmitter release observed in vivo. The release is triggered by depolarization of the nerve terminal membrane and is absolutely dependent on the presence 


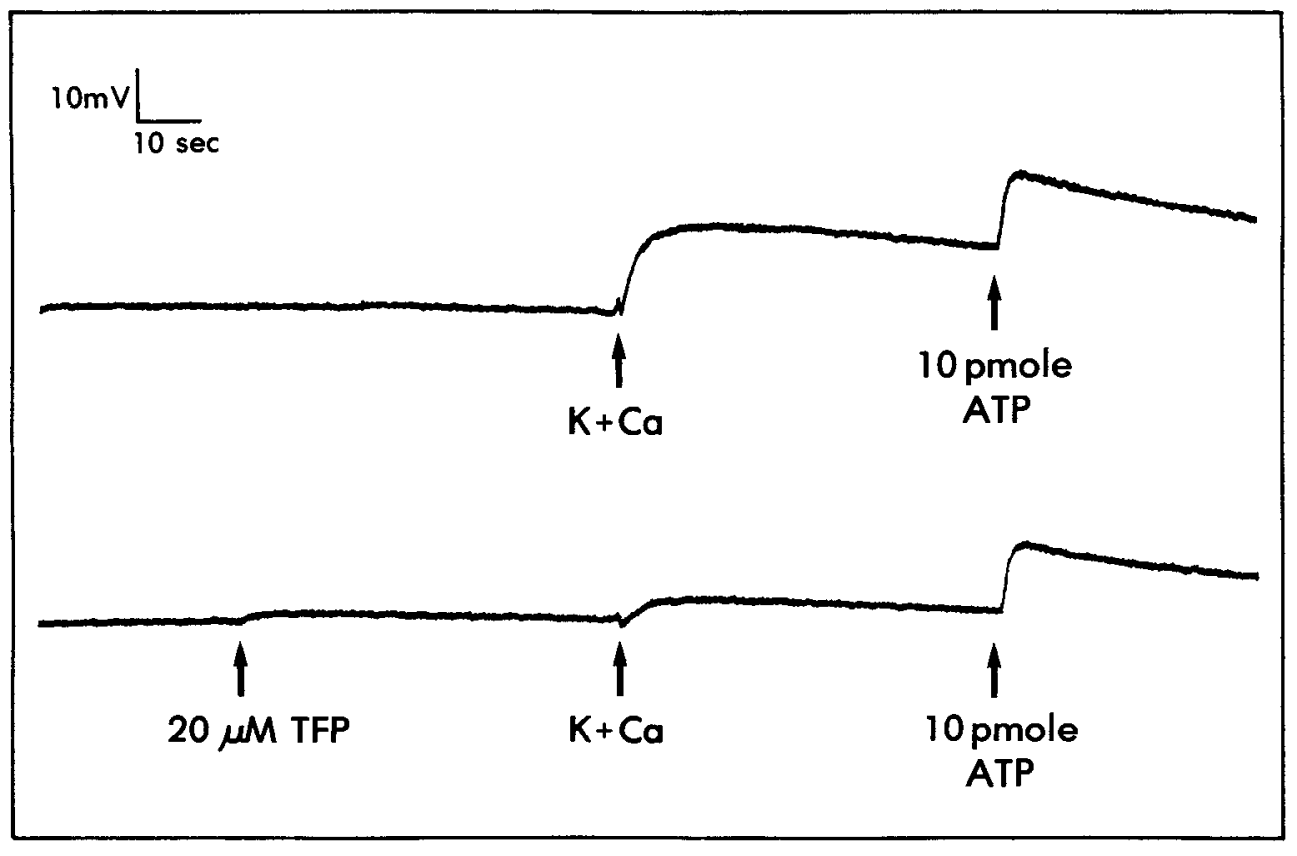

Figure 6. Effect of TFP added directly to assay cuvet. Synaptosomes were added to a cuvet containing $\mathrm{Na}$ $+\mathrm{Ca}$ buffer and $\mathrm{L}-\mathrm{L}$ to give a final volume of $450 \mu \mathrm{l}$. This cuvet was placed in the luminometer to monitor ATP release. In the lower trace, $50 \mu 1$ of $200 \mu \mathrm{M}$ TFP in $\mathrm{Na}+\mathrm{Ca}$ buffer was added directly to the cuvet; $0.5 \mathrm{ml}$ of $\mathrm{K}+\mathrm{Ca}$ depolarizing medium was added 1 min later, followed by an ATP standard. of external $\mathrm{Ca}^{2+}$. It appears that this release is from synaptic terminals, rather than any contaminating structures in the synaptosomal preparation. This system thus provides a means of studying transmitter release in a simple, isolated system that is amenable to biochemical analysis.

The parallel behavior of ATP and ACh is this system is noteworthy. Not only are both released in a depolarization-stimulated, $\mathrm{Ca}^{2+}$-dependent manner, but TFP completely blocks the release of both compounds. This correlation suggests that ATP and $\mathrm{ACh}$ are being released by the same process from a common source, namely, synaptic vesicles. Even stronger support comes from the finding that ACh and ATP are released in a constant ratio of $2.3: 1$, in good agreement with the ratio of $2.8: 1$ found

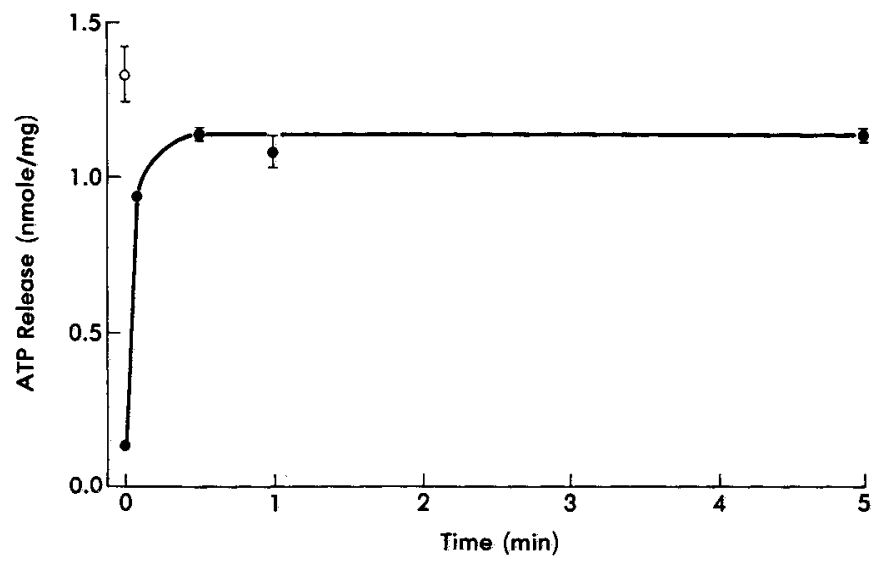

Figure 7. Reversibility of TFP inhibition of ATP release. Synaptosomes were preincubated with $20 \mu \mathrm{M}$ TFP in $\mathrm{Na}(0 \mathrm{Ca})$ buffer for $5 \mathrm{~min}$ at room temperature. Aliquots, $10 \mu \mathrm{l}$, of these pretreated synaptosomes were then diluted 100 -fold with $\mathrm{Na}(+\mathrm{Ca})$ containing $\mathrm{L}-\mathrm{L}$, giving a final concentration of TFP of $2 \mu \mathrm{M}$. After incubation at room temperature for the indicated times, synaptosomes were depolarized with $\mathrm{K}(+\mathrm{Ca})$ solution and the ATP release quantitated. The open circle indicates ATP release from control synaptosomes not preincubated with TFP. The amount of synaptosomal protein used for each assay point was $6.5 \mu \mathrm{g}$. Error bars indicate range of duplicate determinations. in purified synaptic vesicles from the same source (Wagner et al., 1978). These data support a model in which stimulation of this in vitro system results in the fusion of synaptic vesicles with the plasma membrane of the isolated nerve terminals, resulting in the exocytosis of the entire vesicle contents into the medium.

Although the release of both ACh and ATP has been observed from electric organ synaptosomes, the relative amounts reported in such studies have varied. There are reports that no ATP is released (Michaelson, 1978), as well as reports that ATP release occurs but in amounts too small to represent exocytosis of vesicle contents (Israel and Meunier, 1978; Morel and Meunier, 1981). Several factors may account for the observed differences. In some experiments, $\mathrm{ACh}$ was quantitated by the release of ${ }^{14} \mathrm{C}$-acetate-labeled ACh (Morel and Meunier, 1981), a method that preferentially labels the cytoplasmic pool of $\mathrm{ACh}$ and not the ACh contained in vesicles. Israel and Lesbats (1981) have shown that the $\mathrm{ACh}$ released from their preparation by gramicidin or A23187 comes from the same pool that is released by freeze-thawing, which presumably represents cytoplasmic $\mathrm{ACh}$. Indeed, it has been shown that disrupted and refilled synaptosomes can release ACh from their cytoplasm (Israel et al., 1981).

The explanation for these different results may rest in the presence of at least 2 apparently separate routes of $\mathrm{ACh}$ relcase from cholinergic terminals. The route normally associated with synaptic transmission is made up of many quanta, each consisting of about 10,000 molecules of ACh (Kuffler and Yoshikami, 1975). This form of release is $\mathrm{Ca}^{2+}$ dependent and is triggered by depolarization of the nerve terminal. This release also seems most likely to be mediated by exocytosis of vesicle contents, a conclusion supported by the results presented here. A second type of $\mathrm{ACh}$ release is a tonic, nonquantal release that occurs even in the absence of nerve activity (Katz and Miledi, 1977). The actual amount of $\mathrm{ACh}$ released by this second route is quite large, constituting about $98 \%$ of $\mathrm{ACh}$ released at rest (Fletcher and Forrester, 1975). Even during stimulation, nonquantal release may make up a substantial fraction of the total ACh release (Kelly et al., 1979). It is not clear at present whether this nonquantal release of $\mathrm{ACh}$ is affected by $\mathrm{Ca}^{2+}$ or depolar- 


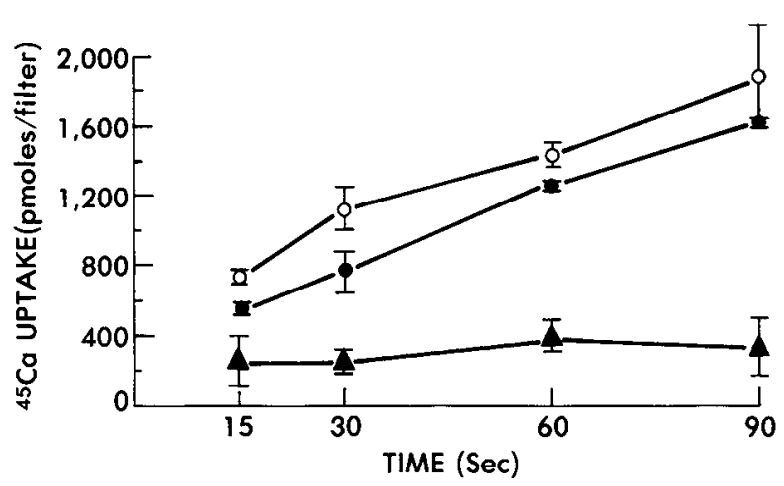

Figure 8. Calcium uptake by synaptosomes. Synaptosomes were preincubated in the presence or absence of $20 \mu_{\mathrm{M}}$ TFP in Na(0Ca) buffer for $3 \mathrm{~min}$ at room temperature. Aliquots of this suspension were added to an equal volume of stimulating solutions containing $10^{5} \mathrm{dpm}{ }^{45} \mathrm{Ca} / \mu \mathrm{l}$ in $\mathrm{Na}(+\mathrm{Ca}), \mathbf{\Delta} ; \mathrm{K}(\mid \mathrm{Ca}), \mathrm{O}$; or $\mathrm{K}(+\mathrm{Ca})$ and $20 \mu \mathrm{M} \mathrm{TFP}$, $\bullet$. After incubation for the appropriate times, these samples were diluted with $\mathrm{Na}(+\mathrm{Ca})$ medium at $0^{\circ} \mathrm{C}$ and filtered with prewashed $0.22 \mu \mathrm{m}$ Millipore filters. The filters were washed twice with cold $\mathrm{Na}(+\mathrm{Ca})$ buffer, dried, and counted in a scintillation counter. In this experiment, there was 65 $\mu \mathrm{g}$ synaptosomal protein/filter. Data shown are the means $\pm \mathrm{SD}$ of 3 determinations.

ization. One limitation of biochemical measurements of total ACh released from nerve terminal preparations is that they measure the sum of the quantal and nonquantal releases. Clearly some preparations may be more advantageous for looking at one or the other form of release, depending on the relative magnitudes of the 2 processes. In addition, the shorter the time resolution of the measurements, the more prominent will be the contribution made by quantal release; the extreme case of this is electrophysiological measurements, in which only the phasic quantal release is normally seen. An alternative approach to examining quantal release selectively is to monitor another vesicle component that is not released directly from the cytoplasm; this report demonstrates that ATP can be used for this purpose.

In the experimental system described here, in which rapid changes in the amounts of ACh and ATP in the bathing medium were measured, the release of ACh and ATP occurred in parallel, consistent with a model in which synaptic vesicles are the source of the depolarization and Ca-dependent secretion. A different model, in which ACh and ATP are released from the cytoplasm through channels, cannot be completely ruled out. However, the present data place severe constraints on such a model. If ACh and ATP were released through 2 independent channels, such channels would be required to produce fluxes of the 2 compounds in a ratio equivalent to that found in synaptic vesicles and to respond to the same stimuli and inhibitors. Alternatively, the coordinate inhibition of ACh and ATP release could be explained if the same channel carried both compounds. However, such a model would require a single channel to be permeable to both the positively charged $\mathrm{ACh}$ and the negatively charged ATP in the proper ratio. In view of this model, it would be interesting to determine the ATP permeability of the recently described ACh-transporting component of synaptic membranes (Birman et al., 1986). However, the similarity between the release ratio and that found in vesicles suggests that the most likely source of the ACh and ATP observed here is the synaptic vesicles. Cytoplasmic release of $\mathrm{ACh}$ is unlikely to be the basis of the phasic secretion process studied here, although it may play a role in other functions of cholinergic synapses, such as

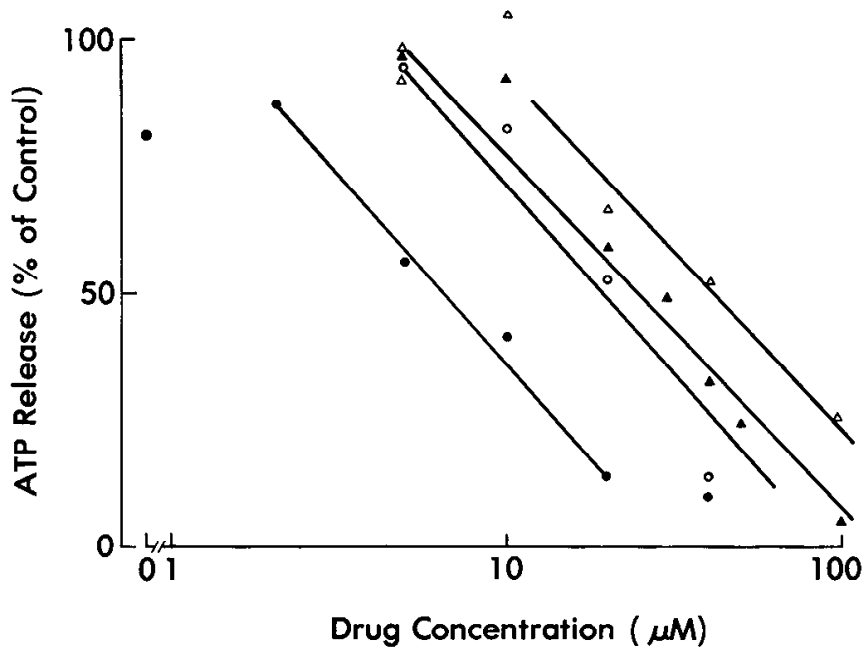

Figure 9. Inhibition of ATP release by TFP analogs. Synaptosomes were preincubated in $\mathrm{Na}(0 \mathrm{Ca})$ medium with the addition of varying amounts of the indicated drugs. Stimulation was then carried out as previously described, using $\mathrm{K}(+\mathrm{Ca})$ solutions and drugs. The drugs themiselves had no effect on the assay. Data shown were collected on different days and are therefore normalized to maximal release in the absence of inhibitor. Drugs used were TFP $(\bullet), W-7(0)$, promethazine $(\Delta)$, and $\mathrm{W}-5(\triangle)$.

those involved in long-term changes or trophic effects.

As shown here, calmodulin antagonists have a dramatic effect on blocking the stimulated release of both ACh and ATP from electric organ synaptosomes. These drugs are highly effective in blocking a variety of calmodulin-mediated cellular processes and have been shown to block secretion in other systems (Douglas and Nemeth, 1982; Knight and Baker, 1982), as well as in the fusion of muscle cells (Bar-Sagi and Prives, 1983). In some systems, TFP acts on the $\mathrm{Ca}^{2+}$ channel; thus, Wada et al. (1983) found that $10 \mu \mathrm{M}$ TFP inhibited more than $90 \%$ of the ${ }^{45} \mathrm{Ca}$ uptake by adrenal chromaffin cells in $1 \mathrm{~min}$. However, using permeabilized chromaffin cells, Knight and Baker (1982) showed that phenothiazines have an inhibitory effect on secretion even when the Ca channel is bypassed. The data presented here indicate that TFP, in concentrations sufficient to block transmitter release completely, has little effect on ${ }^{45} \mathrm{Ca}$ influx into electric organ synaptosomes, suggesting that TFP acts at a step subsequent to increased intracellular calcium, such as the fusion event itself.

Two possible mechanisms for the inhibitory action of the drugs referred to as calmodulin antagonists may be suggested. First, calmodulin itself may be the $\mathrm{Ca}^{2+}$ recognition molecule that triggers" exocytosis. This model would require the presence of a calmodulin binding site on either the synaptic vesicle or the presynaptic plasma membrane; such a binding site has, in fact, been described (Hooper and Kelly, 1984). However, the relative effectiveness of a number of different calmodulin antagonists seen in the present experiments differs markedly from the affinities seen with isolated calmodulin. Specifically, while promethazine is 34-fold less cffcctive than TFP in inhibiting calcium-calmodulin activation of phosphodiesterase $\left(\mathrm{IC}_{50} \mathrm{~s}\right.$ of 340 and $10 \mu \mathrm{M}$ : Levin and Weiss, 1976), the concentration required for half-maximal inhibition of neurosecretion is only about 4 times that of TFP. Similarly, although the observed $\mathrm{IC}_{50}$ of $18 \mu \mathrm{M}$ for $\mathrm{W}-7$ is similar to the $K_{\mathrm{d}}$ reported for its binding to calmodulin $(11 \mu \mathrm{M})$, the difference between $\mathrm{W}-5$ and $\mathrm{W}-7$ is 
less than the 4 - to 8 -fold greater affinity of W-7 seen with calmodulin (Hidaka et al., 1981).

Although care must be taken in interpreting this result because of the uncertainties in the drug concentrations at the active site, it should be noted that other $\mathrm{Ca}$-binding proteins exhibit relative affinities for these drugs that differ from calmodulin; synexin is one example of such a protein. The ability of synexin to aggregate chromaffin granules is also inhibited by phenothiazines, and the half-maximal concentration of promethazine is 4 times that of TFP (Pollard et al., 1983). The effect of the compounds W-5 and $\mathrm{W}-7$ on synexin has not been determined.

The differences in affinity of other cellular proteins for "calmodulin antagonists" suggest an alternative mechanism for the inhibition of neurosecretion by TFP. It is now known that calmodulin is only one of a family of proteins that can both interact with $\mathrm{Ca}^{2+}$ and bind phenothiazines (Moore and Dedman, 1982). The "calmodulin antagonists" also affect other proteins such as protein kinase $\mathrm{C}$, which has both Ca-binding sites and hydrophobic sites (Mori et al., 1980). The site of action of TFP in inhibiting neurosecretion may therefore not be calmodulin itself but a related protein that is similar in its ability to bind both $\mathrm{Ca}^{2+}$ and phenothiazines. Such a molecule could be an activator like calmodulin, an enzyme-like kinase C (Pozzan et al., 1984), or it could be involved in the fusion event itself in a manner similar to viral fusase molecules (White et al., 1982), which undergoes a conformational change exposing a hydrophobic region that inserts into nearby membranes and thus, apparently, triggers fusion. It is interesting to note that virus-induced fusion is inhibited by phenothiazines (Poste and Reeve, 1972), as is the fusion of cultured muscle cells (Bar-Sagi and Prives, 1983). Additional experiments are clearly required to distinguish between the models presented here. It may be possible, for example, to use the affinity of certain Ca-binding proteins for phenothiazines to isolate possible candidates from nerve terminals.

Note added in proof. Yeager et al. (1987) have recently made use of the release of ATP from cholinergic synaptosomes as a marker for transmitter release in order to study the properties of a Ca channel antagonist. They have demonstrated that Conus toxin, known to block $\mathrm{Ca}$ channels in other systems, inhibits the release of ATP from depolarized synaptosomes by blocking the voltage-sensitive presynaptic $\mathrm{Ca}$ channels.

\section{References}

Bar-Sagi, D., and J. Prives (1983) Trifluoperazine, a calmodulin antagonist, inhibits muscle cell fusion. J. Cell Biol. 97: 1375-1380.

Birman, S., M. Israel, B. Lesbats, and N. Morel (1986) Solubilization and partial purification of a presynaptic membrane protein ensuring calcium-dependent acetylcholine release from proteoliposomes. J. Neurochem. 47: 433-444.

Bradford, M. M. (1976) A rapid and sensitive method for the quantitation of microgram quantities of protein utilizing the principle of protein-dye binding. Anal. Biochem. 72: 248-254.

Bruni, A., and G. F. Azzone (1964) The sites of action of atractyloside and oligomycin in the mitochondrial energy-transfer system. Biochim. Biophys. Acta 93: 462-474.

Cheng, K., J. J. Lambert, E. G. Henderson, H. Smilowitz, and P. M. Epstein (1981) Postsynaptic inhibition of neuromuscular transmission by trifluoperazine. J. Pharmacol. Exp. Ther. 217: 44-50.

Creutz, C. E., C. J. Pazoles, and H. B. Pollard (1978) Identification and purification of an adrenal medullary protein (synexin) that causcs calcium-dependent aggregation of isolated chromaffin granules. J. Biol. Chem. 253: 2858-2866.

DeLorenzo, R. J. (1982) Calmodulin in neurotransmitter release and synaptic function. Fed. Proc. 41: 2265-2272.
Dodge, F. A., and R. Rahamimoff (1967) Cooperative action of calcium ions in transmitter release at the neuromuscular junction. $\mathrm{J}$. Physiol. (Lond.) 193: 419-432.

Douglas, W. W., and E. F. Nemeth (1982) On the calcium receptor activating exocytosis: Inhibitory effects of calmodulin-interacting drugs on rat mast cells. J. Physiol. (Lond.) 323: 229-244.

Fletcher, P., and T. Forrester (1975) The effect of curare on the release of acetylcholine from mammalian motor nerve terminals and an estimate of quantum content. J. Physiol. (Lond.) 251: 131-144.

Hidaka, H., Y. Sasaki, T. Tanaka, T. Endo, S. Ohno, Y. Fujii, and T. Nagata (1981) N-(6-aminohexyl)-5-chloro-1-naphthalene-sulfonamide, a calmodulin antagonist, inhibits cell proliferation. Proc. Natl. Acad. Sci. USA 78: 4354-4357.

Hooper, J. E., and R. B. Kelly (1984) Calmodulin is tightly associated with synaptic vesicles independent of calcium. J. Biol. Chem. 259: 148-153.

Israel, M., and A. Lesbats (1981) Continuous determination by a chemiluminescent method of acetylcholine release and compartmentation in Torpedo electric organ synaptosomes. J. Neurochem. 37: 1475-1483.

Israel, M., and F. M. Meunier (1978) The release of ATP triggered by transmitter action and its possible physiological significance: Retrograde transmission. J. Physiol. (Paris) 74: 488-490.

Israel, M., A. Lesbats, and R. Manaranche (1981) ACh release from osmotically shocked synaptosomes refilled with transmitter. Nature 294: 474-475.

Israel, M., B. Lesbats, N. Morel, R. Manaranche, T. Gulik-Krzywicki, and J.C. Dedieu (1984) Reconstitution of a functional synaptosomal membrane possessing the protein constituents involved in acctylcholine translocation. Proc. Natl. Acad. Sci. USA 81: 277-281.

Karl, D. M., and O. Holm-Hansen (1976) Effects of luciferin concentration on the quantitative assay of ATP using crude luciferase preparations. Anal. Biochem. 75: 100-112.

Katz, B., and R. Miledi (1977) Transmitter leakage from motor nerve endings. Proc. R. Soc. London [Biol.] 196: 59-72.

Kelly, R. B., J. W. Deutsch, S. S. Carlson, and J. A. Wagner (1979) Biochemistry of neurotransmitter release. Annu. Rev. Neurosci. 2: 399-446.

Kenigsberg, R. L., and J. M. Trifaro (1985) Microinjection of calmodulin antibodies into cultured chromaffin cells blocks catecholamine release in response to stimulation. Neuroscience 14: 335-347.

Knight, D. E., and P. F. Baker (1982) Calcium-dependence of catecholaminc relcasc from bovinc adrenal medullary cells aftcr cxposure to intense electric fields. J. Membr. Biol. 68: 107-140.

Kuffler, S. W., and D. Yoshikami (1975) The number of transmitter molecules in a quantum: An estimate from iontophoretic application of acetylcholine at the neuromuscular synapse. J. Physiol. (Lond.) 251: 465-482.

Levin, R. M., and B. Weiss (1976) Mechanism by which psychotropic drugs inhibit adenosine cyclic $3^{\prime}, 5^{\prime}$-monophosphate phosphodiesterase of brain. Mol. Pharmacol. 12: 581-589.

Llinás, R., M. Sugimori, and S. M. Simon (1982) Transmission by presynaptic spike-like depolarization in the squid giant synapse. Proc. Natl. Acad. Sci. USA 79: 2415-2419.

Meunier, F. M. (1984) Relationship between presynaptic membrane potential and acetylcholine release in synaptosomes from Torpedo clcctric organ. J. Physiol. (Lond.) 354: 121-137.

Michaelson, D. M. (1978) Is presynaptic acetylcholine release accompanied by the secretion of the synaptic contents? FEBS Lett. 89: 5153.

Miljanich, G. P., A. R. Brasier, and R. B. Kelly (1982) Partial purification of presynaptic plasma membrane by immunoadsorption. $\mathbf{J}$. Cell Biol. 94: 88-96.

Moore, P., and J. R. Dedman (1982) Calcium-dependent protein binding to phenothiazine columns. J. Biol. Chem. 257: 9663-9667.

Morel, N., and F. M. Meunier (1981) Simultaneous release of acetylcholine and ATP from stimulated cholinergic synaptosomes. J. Neurochem. 36: 1766-1773.

Morel, N., M. Israel, R. Manaranche, and P. Mastour-Franchon (1977) Isolation of pure cholinergic nerve endings from Torpedo electric organ. J. Ccll Biol. 75: 43-55.

Mori, T., Y. Takai, R. Minakuchi, B. Yu, and Y. Nishizuka (1980) Inhibitory action of chlorpromazine, dibucaine, and other phospholipid-interacting drugs on calcium-activated, phospholipid-dependent protein kinase. J. Biol. Chem. 255: 8378-8380. 
Pollard, H. B., J. H. Scott, and C. E. Creutz (1983) Inhibition of synexin activity and exocytosis from chromaffin cells by phenothiazine drugs. Biochem. Biophys. Res. Commun. 113: 908-915.

Poste, G., and P. Reeve (1972) Inhibition of cell fusion by local anesthetics and tranquilizers. Exp. Cell Res. 72: 556-559.

Pozzan, T., G. Gatti, N. Dozio, L. M. Vicentini, and J. Meldolesi (1984) $\mathrm{Ca}^{2+}$-dependent and -independent release of neurotransmitters from PC1 2 cells: A role for protein kinase $\mathrm{C}$ activation. J. Cell Biol. 99. 628-638.

Silinsky, E. M. (1975) On the association between transmitter secretion and the release of adenine nucleotides from mammalian motor nerve terminals. J. Physiol. (Lond.) 247: 145-162.

Steinhardt, R. A., and J. M. Alderton (1982) Calmodulin confers calcium sensitivity on secretory exocytosis. Nature 295: 154-195.

Wada, A., N. Yanagihara, F. Izumi, S. Sakurai, and H. Kobayashi (1983) Trifluopenazine inhibits ${ }^{45} \mathrm{Ca}^{++}$uptake and catecholamine secretion and synthesis in adrenal medullary cells. J. Neurochem. 40: 481-486.
Wagner, J. A., S. S. Carlson, and R. B. Kelly (1978) Chemical and physical characterization of cholinergic synaptic vesicles. Biochemistry $17: 1199-1206$

White, J., A. Helenius, and M.-J. Gething (1982) Hemagglutinin of influenza virus expressed from a cloned gene promotes membrane fusion. Nature 300: 658-659.

Whittaker, V. P., W. B. Essman, and G. H. C. Dowe (1972) The isolation of pure cholinergic synaptic vesicles from the electric organs of elasmobranch fish of the family Torpedinidae. Biochem. J. 128: 833-845.

Yagi, K., M. Yazawa, S. Kakiuchi, M. Ohshima, and K. Venishi (1978) Identification of an activator protein for myosin light chain kinase as the $\mathrm{Ca}^{++}$-dependent modulator protein. J. Biol. Chem. 253: 13381340.

Yeager, R. E., D. Yoshikami, J. Rivier, L. J. Cruz, and G. P. Miljanich (1987) Transmitter release from presynaptic terminals of electric organ: Inhibition by the calcium channel antagonist, Omega Conus toxin. J. Neurosci. 7: 2390-2396. 